ORIGINAL ARTICLE ARTIGO ORIGINAL

\title{
Cost variation of antipsychotics in the public health system in Brazil: the implication for health resource use
}

\author{
A variação de custos de antipsicóticos no sistema público \\ de saúde do Brasil: as implicações para o uso de recursos \\ Denise Razzouk
}

DOI: 10.21115/JBES.v9.suppl1.49-57

\section{Keywords:}

antipsychotics agents, costs and cost analysis, community mental health services, health policy, mental disorders, resource allocation

\author{
Palavras-chave: \\ antipsicóticos, custo e análise \\ de custo, serviços comunitários \\ de saúde mental, políticas de \\ saúde, transtornos mentais, \\ alocação de recursos
}

\begin{abstract}
Objective: This study aimed to verify the variation on antipsychotics costs according to four unit costs paid by public health providers in Brazil. Methods: This cross-sectional study used the health provider perspective and bottom-up approach to evaluate 134 subjects with mental disorders, in regular use of antipsychotics, and living in 20 residential services in the city of Sao Paulo between 2011 and 2012. They were assessed for psychiatric diagnosis, the severity of symptoms, quality of life, independent living skills, pattern of health service use and treatments. The Brazilian version of Client Socio-demographic Services Receipt Inventory (ISDUCS) was used to assess health service and medication use. Four different values of unit costs for each antipsychotic were extracted from Medication Price Database (Banco de Preços de Saúde) by the Ministry of Health, Brazil. Results: Variability on the unit costs for chlorpromazine was found by 25,600 fold to the lowest values. Similarly, mean costs of chlorpromazine use per capita per diem varied between BRL 0.55 and BRL 357.87, that is, a difference by 650 fold to the lowest value. Conclusion: The great variability in the unit costs paid by public health providers for all antipsychotics hinders any guideline recommendation for the best cost-saving choice of antipsychotics. It is paramount to proceed cost-effectiveness studies verifying acceptable thresholds for treatments according to the national budget. Yet, monitoring public resource use on the antipsychotic purchasing is imperative to avoid waste of public resources.
\end{abstract}

\section{RESUMO}

Objetivo: Este estudo verificou a variação de custos do antipsicóticos de acordo com quatro valores de unidade de custos pagas pelos provedores públicos no Brasil. Métodos: Estudo transversal utilizou a perspectiva dos provedores públicos de saúde e abordagem bottom-up para avaliar 134 indivíduos com transtornos mentais em uso regular de antipsicóticos, residindo em 20 residências terapêuticas na cidade de São Paulo entre 2011 e 2012. Foram mensurados os diagnósticos psiquiátricos, a gravidade dos sintomas, a qualidade de vida, habilidades de vida independente. O Inventário Sociodemográfico de Utilização de Serviços e Custos - ISDUCS (versão do Client Socio-demographic Service Receipt Inventory) foi utilizado para mensurar a frequência de utilização de serviços e de medicamentos. Quatro valores de unidades de custo para os antipsicóticos foram extraídos do Banco de Preços de Saúde do Ministério da Saúde do Brasil. Resultados: A variabilidade entre as unidades de custo para a clorpromazina foi de 25.600 vezes comparada com o menor valor, e o custo médio da clorpromazina per capita por dia variou de $\mathrm{R} \$ 0,55$ a $\mathrm{R} \$ 357,87$, uma diferença de 650 vezes o menor valor. Conclusão: A grande variabilidade entre as unidades de custos pagas pelo provedor público de saúde dificulta as recomendações dos guias clínicos em termos de escolher o antipsicótico menos custoso como primeira linha, sendo necessários estudos de custo-efetividade para verificar o limite máximo aceitável para a unidade de custo compatível com o orçamento nacional. O monitoramento do uso de recursos públicos para a aquisição de antipsicóticos é imperativo para impedir o desperdício de recursos públicos.

Received on: 07/25/2017 Approved for publication on: 08/16/2017

1. Centre of Mental Health Economics, Department of Psychiatry, Universidade Federal de Sao Paulo, Sao Paulo, SP, Brazil.

Institution of the study: Universidade Federal de Sao Paulo.

Funding: São Paulo Research Foundation (Fapesp) n 53286-3.

Corresponding author: Denise Razzouk. Rua Borges Lagoa, $1{ }^{\circ}$ andar, Vila Clementino

São Paulo, SP, Brazil. CEP: 04038-000. Telephone: +55 (11) 5576-4990.E-mail: drazzouk@gmail.com 


\section{Introduction}

Antipsychotics are the main drugs used for psychotic disorders, being in two major classes: typical and atypical antipsychotics. The former drugs were launched in the 50's and they are much cheaper than the latter drugs launched in the 80 and 90 's. Antipsychotics vary enormously in terms of costs, not only among different classes of drugs but within the same drug from different seller sources (Chimurkar et al., 2014). Atypical antipsychotics, for instance, may be two hundred times more expensive than typical ones (Razzouk et al., 2015) even though no significant differences in the efficacy for psychotic symptoms are found (Knapp \& Razzouk, 2009; Kayo \& Razzouk, 2017; Leucht et al., 2011).

Antipsychotics are usually partially or totally subsidized by the public health system in many countries. The high costs of antipsychotics have an impact on public health budgets (Razzouk et al., 2015; Rosenheck \& Sernyak, 2009; Lindner et al., 2009) and in health insurance companies' reimbursement (Kendall, 2011). Atypical antipsychotics accounted for 93\% of all expenses with expensive drugs delivered by Public Health System in Brazil (Barbosa et al., 2016) even though anti-neoplastic and immunomodulation drugs have been leading the wholesale drug expenditures by the Brazilian Federal Government (Luz et al., 2017).

Cost-effectiveness among antipsychotics is still an open question (Meltzer et al., 2009). The majority of guidelines for psychotic disorders recommend atypical antipsychotics as first line option for high-income settings, while typical antipsychotics are recommended as the first line option for those settings with very limited health budget. However, the majority of cost-effectiveness studies have a conflict of interests (funded by their manufacturers), are modelling studies not representing the real world, and have methodological limitations (Kayo \& Razzouk, 2017). Moreover, there is a scarcity of cost-effectiveness studies in low and middle-income countries (Kayo et al., 2015; Lubinga et al., 2015). In this regard, economic evaluation can be useful for guiding decision making on how to allocate public financial resources to new technologies and drugs since decision makers take into account the impact of these new technologies/drugs costs to the health budget in terms of feasibility, sustainability, acceptability, coverage, population characteristics and health priority needs (Chisholm et al., 2008).

In Brazil, a middle-income country, there are no published empirical studies on the cost-effectiveness of antipsychotics. One modelling study (Lidner et al., 2009) compared costs among antipsychotics and assessed their impact on the local health budget, and another modelling study compared cost-effectiveness among antipsychotics (Santos et al., 2016). They found opposite results in terms of cost-effectiveness among antipsychotics. Since 2011, the inclusion of new drugs in the package of care in the Brazilian public health system has been analysed by CONITEC's (The Brazilian National Committee for Acquiring New Technology in Public Health System) and their reviewers take into account results from efficacy trials, safety, cost-effectiveness studies and health budget impact analysis (Ministry of Health Brazil, 2016; Silva et al., 2012). Unlike the United Kingdom's drug policies adopting the willing-to-pay thresholds for including new interventions and drugs in the package of care (the highest value accepted to be paid for one unit of health improvement by one health intervention or package of care), Brazil does not adopt a ceiling ratio (Pinto et al., 2016). But one bill for adopting a costeffectiveness threshold is currently under evaluation in the Brazilian Congress.

However, once one drug is approved to be available in the Brazilian public health system, there is a remarkable variation on the maximum costs paid for acquiring it despite the national regulations establishing the maximum drug purchasing prices for the government. Currently, there are fourteen antipsychotics available in the Brazilian public health system. Of those, more than half are the atypical antipsychotics. The Brazilian Prices of Drugs Database (BPS - Banco de Preços de Medicamentos) developed by the Brazilian Ministry of Health is an important tool in terms of data transparency regarding the use of financial health resources. On this database, wholesale acquisition costs are available online by drug, institution, city, manufacturer, the quantity bought, cost per pill, date and other parameters. Unit costs for one antipsychotic may vary in an 895-fold ratio to the lowest value for the same period of time and country (Ministry of Health Brazil, 2017). Of note, the unit costs of one antipsychotic in this database for the same period of time varied from BRL0.3 to BRL268.00. BPS reported some adjustments of these unit costs, using weight mean for each price reported. However, this measure also varies from 0.4 to 14.97, that is, 1:37 ratio to the lowest value. Therefore, if there is a range of values in which antipsychotics may be costeffective, in practice, after allocating resource for acquiring these drugs in a hypothetical range of costs, health providers may acquire them at prices that may compromise the costeffectiveness of antipsychotics and the rational use of health resources.

This study aimed to verify the variation in costs of antipsychotic treatment according to four different values of unit costs paid by public health providers in Brazil using a sample of people with mental disorders in the city of Sao Paulo.

\section{Methods}

A cross-sectional study was carried out in the city of Sao Paulo between 2011 and 2012 to estimate antipsychotic 
costs in a sample of people with moderate and severe mental disorders. This study is part of a research project that evaluated the direct costs of health services for a sample of subjects discharged from long-term psychiatric hospitals. Detailed methodology is described elsewhere (Razzouk et al., 2015). This study was approved by the Ethical Committee of the Secretary of Health for the city of Sao Paulo. Carers and residents were adequately informed of all aspects regarding participation and the purpose of the study, providing a written consent prior to the interviews.

Sample: 134 people were taking antipsychotics regularly in a sample of 147 subjects discharged from psychiatric hospitals to residential services in Sao Paulo. This sub-sample was analysed in terms of use of antipsychotics and mental health services for the previous month of interview.

Local: All subjects lived in 20 residential services in 24hour staffed houses with up to eight residents, located in five regions of the city of Sao Paulo. These services are managed by the Secretary of Health for the city of Sao Paulo and they target people deinstitutionalised from psychiatric services. Each residential service was close to one Centre of Psychosocial Care (CAPS) in which mental health treatment was delivered.

Instruments: Residents were assessed by trained psychiatrists and occupational therapists for diagnosis (MINI International Neuropsychiatric Interview) (Amorim, 2000), the severity of psychiatric symptoms (Clinical Global Impression Scale - CGI) (Haro et al., 2003), quality of life (QLS) (Heinrichs et al., 1984), social behaviour (SBS scale) (Lima et al., 2006), independent living skills (ILSS) (Bandeira et al., 2003) and health service use (ISDUCS) (Sousa et al., 2013).

\section{Estimation of costs}

The Client Sociodemographic and Service Receipt Inventory (CSSRI) (Chisholm et al., 2000) is a semi-structured instrument used to assess social and demographic data, accommodation data, detailed information about treatment, professional visits, and social and health services utilisation. The Client Sociodemographic Service Receipt Inventory (Chisholm, 2000) was translated to Portuguese (Inventário Sociodemográfico de Utilização e Custos de Serviços - ISDUCS) and adapted to the Brazilian context (Sousa et al., 2013; Sousa \& Razzouk, 2017). The CSSRI uses the patient and caregiver as information sources. Direct costs of a package of care included medication use, visits to mental health professionals in CAPS and psychiatric hospitalisations.

A bottom-up approach was used for the estimation of direct costs, according to public health provider perspective. The CSSRI allows calculating health care costs using the modality of service or intervention and the frequency of use. Direct costs of mental health care and treatments for the previous month were estimated for each resident, for the year
2011. Unit costs for drugs were retrieved from BPS's database for the year 2011, city of Sao Paulo, using the highest value available. To explore the variation of unit costs available in BPS database, three values of unit costs of antipsychotics were used: the lowest and the highest value for Brazil and the weight mean for the period between 2016 and 2017. Antipsychotic treatment cost per diem per capita was estimated for each patient, using four unit costs described above.

\section{Results}

A sample of 134 subjects taking antipsychotics regularly was included in this study. Sociodemographic and clinical characteristics are described in Table 1. Mean and standard deviation age was $49.5 \pm 12$ years, mean (SD) length of time living in residential service was $35.5 \pm 16$ months and mean (SD) length of previous time living in a psychiatric hospital was $115.4 \pm 106$ months.

Table 2 presents the pattern of antipsychotic use in terms of dose per day. Polytherapy was common in the sample, almost $42 \%(n=56)$ of the sample presented the regular use of two or more antipsychotics. Almost $45 \%(n=60)$ of the sample used only typical antipsychotics, and 15 (11\%) subjects used depot antipsychotics.

Table 3 shows the variability on the unit costs per antipsychotic, based on data extracted from BPS's database. Among atypical antipsychotics, ratios between the highest to the lowest value of unit cost varied between 1:56 ratio (aripiprazole) and 1:35,000 ratio (risperidone). Among typical antipsychotics, ratios between the highest to the lowest values of unit cost varied between 1:19 (periciazine) and 1:25,600 (chlorpromazine).

The antipsychotic costs per diem per capita using unit costs (for Sao Paulo, the year 2011) varied from BRL0.007 to BRL60.75, mean (SD) BRL 7.45 (13.00). Antipsychotic mean (SD) costs per diem per capita according to the severity of psychiatric symptoms were: BRL $7.96 \pm 14.6$ for mild/no symptoms group ( $n=48$ ) and BRL $7.18 \pm 12.02$ for moderate/ severe symptoms group $(n=86)$.

Table 4 shows antipsychotic total costs per diem according to the values of four unit costs (described above). For instance, olanzapine costs per diem varied from BRL 0.49 to BRL392.70 according to different unit costs for eighteen patients using dose between 10 and $30 \mathrm{mg}$ per day. Similarly, antipsychotic total costs per diem for the whole sample varied between BRL 74.00 and BRL 47,954.00. Regarding antipsychotic average costs per capita per diem, it ranged from BRL 0.55 to BRL358.00, that is, a difference of 650 fold to the lowest costs. Atypical antipsychotics accounted for $76 \%$ of total costs of antipsychotics, a difference between atypical/typical by 381 -fold in the mean costs per capita per diem. 
Table 1. Socio and demographic and psychiatric characteristics $(n=134))$

\begin{tabular}{|c|c|c|}
\hline & $\mathbf{N}$ & $\%$ \\
\hline \multicolumn{3}{|l|}{ Gender } \\
\hline Male & 67 & 50.0 \\
\hline Female & 67 & 50.0 \\
\hline \multicolumn{3}{|l|}{ Education } \\
\hline Illiterate & 24 & 18 \\
\hline Elementary & 96 & 72.1 \\
\hline Secondary & 10 & 7.6 \\
\hline College & 3 & 2.3 \\
\hline \multicolumn{3}{|l|}{ Income (monthly) } \\
\hline Less than BRL501.00 & 7 & 5.2 \\
\hline Between BRL 501.00 and BRL1000.00 & 91 & 67.9 \\
\hline Higher than BRL1000.00 & 3 & 2.2 \\
\hline None & 33 & 24.6 \\
\hline \multicolumn{3}{|l|}{ Lifetime Diagnosis (MINI Interview) } \\
\hline Any psychosis & 108 & 80.6 \\
\hline Alcohol or drug use without psychotic symptoms & 7 & 5.1 \\
\hline Unipolar depression & 2 & 1.5 \\
\hline None & 12 & 9.0 \\
\hline Missing & 5 & 3.7 \\
\hline \multicolumn{3}{|l|}{ Severity of psychiatric symptoms (CGI-scale) } \\
\hline Mild or no symptoms & 48 & 35.8 \\
\hline Moderate to Severe & 86 & 64.2 \\
\hline
\end{tabular}

Table 2. Mean dose of antipsychotics per day $(n=134)$

\begin{tabular}{|c|c|c|c|c|c|}
\hline & $\mathrm{N}(\%)$ & Minimum & Maximum & Mean & SD \\
\hline & & $\mathrm{mg} / \mathrm{day}$ & $\mathrm{mg} / \mathrm{da}$ & $\mathrm{mg} / \mathrm{day}$ & $\mathrm{mg} / \mathrm{day}$ \\
\hline \multicolumn{6}{|c|}{ Atypical antipsychotics $(n=73)$} \\
\hline Olanzapine & $18(13.4)$ & 10 & 30 & 16,11 & 5,83 \\
\hline Risperidone & $28(20.9)$ & 1 & 8 & 4,32 & 2,21 \\
\hline Quetiapine & $12(8.9)$ & 300 & 800 & 508,33 & 167,65 \\
\hline Clozapine & $8(5.9)$ & 150 & 700 & 331,25 & 175,13 \\
\hline Ziprasidone & $7(5.0)$ & 80 & 240 & 160,00 & 65,32 \\
\hline Aripiprazole & $2(1.5)$ & 30 & 30 & - & - \\
\hline \multicolumn{6}{|c|}{ Typical antipsychotics $(\mathrm{n}=91)$} \\
\hline Haloperidol & $60(44.8)$ & 1 & 25 & 9,60 & 5,02 \\
\hline Chlorpromazine & $44(32.8)$ & 100 & 800 & 250,57 & 175,74 \\
\hline Periciazine & $11(8.2)$ & 5 & 60 & 25,27 & 20,22 \\
\hline Levomepromazine & $6(4.5)$ & 50 & 300 & 175,00 & 108,40 \\
\hline Tioridazine & $1(0.75)$ & 300 & 300 & & \\
\hline \multicolumn{6}{|l|}{ Depot antipsychotics } \\
\hline & & $\begin{array}{l}\text { Minimum } \\
\mathrm{mg} / \mathrm{month}\end{array}$ & $\begin{array}{l}\text { Maximum } \\
\mathrm{mg} / \text { month }\end{array}$ & Mean mg/month & $\mathrm{SD} \mathrm{mg} / \mathrm{month}$ \\
\hline Pipotiazine & $2(1.5)$ & 50 & 75 & 62.5 & \\
\hline Haldol decanoate & $13(9.7)$ & 50 & 300 & 149.85 & 78.16 \\
\hline
\end{tabular}

$\mathrm{SD}=$ standard deviation. 
Table 3. Unit costs per pill by antipsychotic drugs in Brazilian currency (BRL)

\begin{tabular}{|c|c|c|c|c|}
\hline & Unit costs $1^{*}$ & Unit costs $2^{*}$ & Unit costs $3^{*}$ & Unit costs $4^{*}$ \\
\hline & $\begin{array}{l}\text { BPS for Sao Paulo } \\
2011\end{array}$ & $\begin{array}{c}\text { BPS lowest value } \\
2016-17\end{array}$ & $\begin{array}{l}\text { BPS highest } \\
\text { value 2016-17 }\end{array}$ & $\begin{array}{c}\text { BPS } \\
\text { Weight mean } \\
\text { 2016-17 }\end{array}$ \\
\hline \multicolumn{5}{|l|}{ Atypical antipsychotics } \\
\hline Olanzapine 10 mg & 20.0 & 0.34 & 268.74 & 2.38 \\
\hline Risperidone 2 mg & 0.05 & 0.007 & 245 & 0.12 \\
\hline Quetiapine 200 mg & 7.33 & 0.15 & 242.76 & 0.47 \\
\hline Clozapine 100 mg & 2.0 & 1.75 & 16.01 & 1.90 \\
\hline Ziprasidone 80 mg & 7.2 & 0.02 & 0.74 & 0.65 \\
\hline Aripiprazole 30 mg & 29.2 & 0.53 & 29.35 & 0.69 \\
\hline \multicolumn{5}{|l|}{ Typical antipsychotics } \\
\hline Haloperidol 5 mg & 0.013 & 0.02 & 0.74 & 0.65 \\
\hline Chlorpromazine100 mg & 0.05 & 0.005 & 128.00 & 0.15 \\
\hline Periciazine $4 \%$ cost per drop** & 0.28 & 0.003 & 0.02 & 0.015 \\
\hline Levomepromazine 100 mg & 0.26 & 0.02 & 290.00 & 0.67 \\
\hline Tioridazine 100 mg & 0.18 & 0.117 & 13.5 & 0.69 \\
\hline \multicolumn{5}{|l|}{ Depot antipsychotics ${ }^{* * *}$} \\
\hline Pipotiazine 25 mg & 11.61 & 34.00 & 64.00 & - \\
\hline Haldol decanoate 50 mg & 1.35 & 0.171 & 135.00 & 5.45 \\
\hline
\end{tabular}

* Unit costs 1 = the highest values for the city of Sao Paulo, for the year 2011, were extracted from BPS; Unit costs 2 = the lowest values of unit costs paid by health providers in Brazil for the period between 2016 and 2017; Unit costs 3 = the highest values of unit costs paid by health providers in Brazil for the period between 2016 and 2017; Unit costs 4 = weight mean for unit costs estimated by BPS taking into account the amount of pills bought, prices paid and one standard deviation. All data on unit costs are available on BPS website.

** Each bottle has $20 \mathrm{ml}, 1 \mathrm{ml}=40$ drops; 1 drop $=1 \mathrm{mg}$. Then, total price per bottle/800 drops $=$ costs per drop.

*** Depot antipsychotics are long-acting injectable drugs. Unit costs refer to costs per unit per month.

\section{Discussion}

This study illustrates the variation of antipsychotics costs according to different unit costs available in the Ministry of Health Database of Drug Prices (Ministry of Health, Brazil, 2017) in a sample of 134 subjects with moderate and severe mental disorders in the city of Sao Paulo. Risperidone (atypical), Chlorpromazine and Levomepromazine (both typical antipsychotics) presented the greatest cost variability comparing lowest and highest values of unit costs $(35,000$ fold, 25,600 fold, 15,263 fold, respectively). But a huge unit cost variation was found for all antipsychotics. Clozapine presented the lowest cost variation, although its costs per capita per diem were higher than other drugs according to three different values of unit costs. Similarly, olanzapine costs per capita diem were higher than other drugs, according to two unit costs. Olanzapine's patent expired after 2011, and during the period of our study, all atypical antipsychotics had active patents, excepting for risperidone. However, even after patent's expiration, olanzapine and clozapine and other atypical antipsychotics have been purchased, in some cases, at the same or higher prices than the patent period
(Razzouk et al., 2015; Lindner et al., 2009). Of note, all unit costs for 2011 used in our study are still in the range of unit costs paid between 2016 and 2017. Among typical antipsychotics, chlorpromazine mean costs per capita per diem varied between BRL 0.55 and BRL 357.87, that is, a difference of 650 fold, while haloperidol was 4 -fold costlier than the former, according to two unit costs.

Similar variations have been reported in the literature, such as the study evaluating antipsychotic prices in the Indian market (Tondare \& Bhave, 2014). They found a price variation of $1137 \%$ for olanzapine and 348\% for haloperidol. However, this study focused on market prices and on outof-pocket expenditures rather than on prices paid by public health providers.

There is a lack of transparency in the cost variation among antipsychotics, especially in modelling studies. The majority of cost-effectiveness studies among antipsychotics have not reported in detail about the range of cost variability among these drugs according to public health payer perspective and how they assessed it through sensitivity analysis. This cost variation might be due to purchasing from different manufacturers (reference and generic drugs), type of 
Table 4. Total antipsychotic costs per diem per drug and mean antipsychotic costs per capita per diem according to four different BPS unit costs $(n=134)$

\begin{tabular}{|c|c|c|c|c|}
\hline & $\begin{array}{c}\text { Unit costs } 1 \\
\text { BRL }\end{array}$ & $\begin{array}{c}\text { Unit costs } 2 \\
\text { BRL }\end{array}$ & $\begin{array}{c}\text { Unit costs } 3 \\
\text { BRL }\end{array}$ & $\begin{array}{c}\text { Unit costs } 4 \\
\text { BRL }\end{array}$ \\
\hline \multicolumn{5}{|l|}{ Total antipsychotic costs per diem } \\
\hline Atypical total $(n=73)$ & 973.63 & 65.01 & $30,604.86$ & 149.74 \\
\hline Olanzapine & 526.05 & 8.84 & $7,068.53$ & 62.57 \\
\hline Risperidone & 3.18 & 0.42 & $15,582.00$ & 7.83 \\
\hline Quetiapine & 224.45 & 4.53 & $7,427.36$ & 14.42 \\
\hline Ziprasidone & 103.16 & 0.27 & 10.60 & 9.34 \\
\hline Aripiprazole & 59.79 & 1.08 & 60.09 & 1.43 \\
\hline Clozapine & 57.00 & 49.87 & 456.28 & 54.15 \\
\hline Typical total $(n=91)$ & 14.35 & 3.12 & $17,184.73$ & 102.73 \\
\hline Haloperidol & 1.57 & 2.29 & 89.36 & 78.74 \\
\hline Chlorpromazine & 6.13 & 0.55 & $14,011.43$ & 16.44 \\
\hline Periciazine & 3.84 & 0.04 & 0.29 & 0.20 \\
\hline Levomepromazine & 2.75 & 0.20 & $3,079.15$ & 7.16 \\
\hline Tioridazine & 0.06 & 0.04 & 4.5 & 0.23 \\
\hline Injectable depot total $(n=15)$ & 3.47 & 5.83 & 164.64 & \\
\hline Pipotiazine depot & 1.93 & 5.63 & 10.63 & - \\
\hline Haloperidol Decanoate & 1.54 & 0.20 & 154 & 6.22 \\
\hline Total costs antipsychotics per day $(n=134)$ & $999.82^{* *}$ & 73.96 & $47,954.22$ & 254.73 \\
\hline \multicolumn{5}{|l|}{ Mean antipsychotic costs per capita per diem } \\
\hline Atypical $(n=73)$ & 60.97 & 0.89 & 419.24 & 2.05 \\
\hline Olanzapine & 29.22 & 0.49 & 392.69 & 3.48 \\
\hline Risperidone & 0.11 & 0.01 & 556.5 & 0.28 \\
\hline Quetiapine & 18.7 & 0.38 & 618.94 & 0.65 \\
\hline Ziprasidone & 14.73 & 0.04 & 1.51 & 1.33 \\
\hline Aripiprazole & 29.9 & 0.54 & 30.03 & 0.71 \\
\hline Clozapine & 7.12 & 6.23 & 53.28 & 6.77 \\
\hline Typical $(n=91)$ & 0.16 & 0.03 & 188.84 & 1.12 \\
\hline Haloperidol & 0.03 & 0.04 & 1.49 & 1.31 \\
\hline Clorpromazine & 0.003 & 0.01 & 318.44 & 0.37 \\
\hline Perciazine & 0.35 & 0.004 & 0.03 & 0.02 \\
\hline Levomeprazine & 0.46 & 0.03 & 513.19 & 1.19 \\
\hline Tioridazine & 0.06 & 0.04 & 4.5 & 0.23 \\
\hline Injectable depot $(n=15)$ & 0.23 & 0.38 & 10.97 & - \\
\hline Pipotiazine depot & 0.96 & 2.82 & 5.32 & - \\
\hline Haloperidol Decanoate depot & 0.12 & 0.01 & 11.85 & 0.48 \\
\hline $\begin{array}{l}\text { Mean antipsychotics costs per } \\
\text { capita diem }(n=134)\end{array}$ & $7.46^{* *}$ & 0.55 & 357.87 & $1.93^{*}$ \\
\hline
\end{tabular}

* Costs per capita ( $n=132$ ), excluded those using pipotiazine; ** Adjusted for 2017-total antipsychotic costs (unit costs 1, 2011) using 5\% discount factor (6 years) would be BRL 746.34 per diem (BRL5.56 per capita per diem), olanzapine BRL392.54; risperidone = BRL2.37, quetiapine BRL167.48, ziprasidone BRL76.98, aripiprazole BRL44.68, clozapine BRL42.53. 
purchasing (routine or judicial decision), geographic region (these drugs are not equally distributed across the country), and by the amount of drug acquired, among other factors. Also, BPS data may be inaccurate in some cases because the inclusion of data on the database is made directly by health providers. Since the creation of Banco de Preços Database (BPS), public health providers are advised to base their purchasing on the prices dealt by other institutions available in BPS. Hypothetically, this practice would allow them to trade lower prices with manufacturers.

In summary, these findings showed that the wide range of values of unit costs hinders comparisons among antipsychotics in terms of cost-saving. This huge variation in the unit costs of antipsychotics has multiple implications, especially for clinical guideline recommendations, costeffectiveness studies, and the monitoring of public resource use.

The first implication of such variation in costs is related to national guideline recommendations for treating psychotic disorders. In Brazil, national guidelines suggest the use of at least one typical antipsychotic as the first line because they are costliest. However, the great variability in the costs of typical antipsychotics (especially for chlorpromazine and levomepromazine) added to the lowest unit costs for risperidone, being similar to the majority of typical antipsychotics, showed that this distinction between costs of drug classes was not always useful for reducing costs in practice. One Brazilian study (Alves et al., 2015) estimated antipsychotic costs according to the average unit costs, using standardised doses recommended in the National Antipsychotic Prescribing Guidelines. The estimation of costs based only on protocol recommendation (Alves et al., 2014) and on the mean value of unit costs could lead to an unreal conclusion on antipsychotic treatment costs. In practice, antipsychotic polytherapy was found in $40 \%$ of our sample. Although the mean dose of each antipsychotic was within the national protocol dose range, the addition of the second antipsychotic represented higher doses than protocol recommendation and additional costs (Razzouk et al., 2015). However, guidelines would be useful if they guide for the best choices on antipsychotic, taking into account benefits for patients, risks (Goff et al., 2017), treatment adherence, comorbidity, and costs. In this regard, Rosenheck and Sernyak (2009) recommend treating schizophrenia in the United States, taking into account cost-effectiveness and adverse effects: first line generic risperidone and typical antipsychotics, second line clozapine, third line quetiapine, ziprasidone, aripiprazole, and fourth line olanzapine.

The second consequence of cost variation among antipsychotics is related to cost-effectiveness ratio among these drugs. There is a lack of published data on the costeffectiveness of antipsychotics in Brazil (Kayo et al., 2015) and, in this regard, it is paramount to explore this cost variation in cost-effectiveness acceptance curves and in sensitivity analysis because health providers might acquire these drugs at higher costs than within an optimal range of cost-effectiveness. One modelling cost-effectiveness study in Brazil (Lindner et al., 2009) showed the variation on antipsychotics unit costs by 10 fold, using one-month regional prices. Another modelling study (Santos et al., 2016) in Brazil, advocated that olanzapine had a probability of $100 \%$ of being cost-effective at costs BRL364.00 per month or BRL12 per day. However, our findings showed that olanzapine costs per diem might be superior, in practice, to those recommended above, depending on the unit costs.

In other words, a drug proven to be cost-effective in a study may not be cost-effective in practice if health provider pays much more than the range of costs tested in sensitivity analysis. Moreover, the quality and accuracy of economic data might influence health decision makers in approving a new intervention. However, conducting cost-effectiveness studies requires choosing valid unit costs and testing them for uncertainty, while ignoring such variability on drug costs may contribute to misleading decisions. ISPOR Task Force recommends as the best practice for measuring drug costs from health manager perspective the use of unit costs based on the price paid per drug unit (Mullins et al., 2010). However, these data are not easily obtainable because of confidentiality constraints or due to multiple sources involved in drug purchase. In this regard, BPS offers an option to assess "real" wholesale prices paid by health providers, and there is a high level of variability among them.

The third issue related to cost variation of unit costs is associated with the patent. We have reported before that the costs of eighteen people taking olanzapine treatment before patent expiration was equivalent to half of psychotropic costs taken by 134 subjects (Razzouk et al., 2015). On average, atypical antipsychotics were 380-fold more expensive than typical ones during the patent period, and currently they remain at least the double of typical antipsychotic costs. The effect on costs of switching reference drugs for generics is not conclusive yet. There are some findings in Finland showing cost-savings in the short and medium term but not in the long-term (Koskinen et al., 2015). Some savings were also observed in other countries (Husselman et al., 2016). It is important to compare the costs and effectiveness of antipsychotics after the expiration of patents because generics may differ from reference brand drugs in terms of effects and, consequently, lead to fewer benefits (Nuss et al., 2004). Drug discontinuation and hospitalisation rate might not be the best outcomes to verify the cost-effectiveness of antipsychotics for treating schizophrenia. Other relevant outcomes, such as patient's quality of life and psychosocial functioning alongside improvements in clinical symptoms 
and adverse effects, should be taken into account (Kayo \& Razzouk, 2017; Knapp \& Razzouk, 2009). Also, some adverse effects are acute, like extra-pyramidal symptoms, while others appear after months or years of treatment, such as cardiovascular and metabolic diseases. Studies on atypical antipsychotics, for instance, with olanzapine, should take into account the risks of diabetes and other metabolic diseases (Rosenheck \& Sernyak, 2009). Metabolic and cardiovascular diseases are associated with a higher prevalence and mortality rate and costs in people with schizophrenia and bipolar disorders (Correll et al., 2017; Elkis et al., 2008). In this regard, long-term prospective evaluations are crucial for deciding on the value of treatment (Goff et al., 2017), although effectiveness differences among antipsychotics are still unproven.

The last issue refers to national drug policies and the use of public resources. While costs analysis and cost-effectiveness are some of the requirements for deciding on the inclusion of new technology/drug in the public health system in Brazil, the huge variability in the price paid per unit of antipsychotics by health providers suggests the lack of awareness of health economic principles applied to resource use. Recently, the Ministry of Health in Brazil established that all prices paid per unit by health providers should be inserted in BPS. This is an important measure to guarantee transparency on resource use, and it may also influence health providers to negotiate medication prices at the optimal level, close to those cost ranges assessed in cost-effectiveness studies. However, there is a need to boost capacity building in Health Economics among health providers in Brazil in order to monitor resource use and evaluate its impact on health outcomes. Moreover, policy targeting drug price control would be beneficial to avoid such huge cost variability.

This study has limitations and results should be analysed accordingly. The sample size was small and not representative of all subjects with psychotic disorders. It is a cross-sectional design with a short-term evaluation. Data on treatment corresponded to the one-month period and any variation on the dose and on the type of antipsychotic used out of this period was not obtained. Unit costs extracted from BPS database might not be representative of all unit costs paid by health providers since BPS use was optional. Yet, these data might be inaccurate because many health providers were responsible for inserting information on costs and error could occur. The study was carried out during the antipsychotic patent period and then unit costs in 2011 would be lower if generic drugs were available. The comparison among the units of costs did not distinguish between generic and brand reference drugs, and the highest value of unit costs might be not representative of the majority of cities. Dispensing drug costs and monitoring examination costs were not computed for examining differences among antipsychotic costs. But this was not the goal of this study.

\section{Conclusion}

To conclude, this was the first study using a bottom-up approach that evaluated the antipsychotic costs used by a sample of people with mental disorders in the city of Sao Paulo, showing huge variability on antipsychotic costs. It would be of great value having national references for unit costs for all drugs as well as developing guidelines to set standards for the use of unit costs based on BPS database for cost-effectiveness analysis. It is recommended to improve health providers' awareness of the best use of public resources and to promote understanding of the main principles of health economics, such as cost-effectiveness and budget health impact. Multiple criteria are relevant for decision analysis regarding the inclusion of new technologies and drugs in the public health system. However, monitoring the best practices on drug and technology use and purchasing is paramount for avoiding resource waste.

\section{Acknowledgments}

Aglae Sousa, Alessandra Siomi, Andrea Cardoso, Guilherme Gregório, Monica Kayo, Jair Mari, Paula Becker.

\section{References}

Alves LCV, Andrade CCD, Brandão CMR. Custo de medicamentos antipsicóticos sob a perspectiva do Sistema Único de Saúde. Brazilian Association of Health Economics, São Paulo. 2014. Available from: http:// abresbrasil.org.br/trabalhos/custo-de-medicamentos-antipsicoticos-sobperspectiva-do-sistema-unico-de-saude.html. Acesso em: 11/07/2017.

Amorim P. Mini International Neuropsychiatric Interview (MINI): validação de entrevista breve para diagnóstico de transtornos mentais. Rev Bras Psiquiatr. 2000;22:105-15.

Bandeira M, Lima LA, Gonçalves S. Qualidades psicométricas no papel da Escala de Habilidades de Vida Independente de pacientes psiquiátricos (ILSS-BR). Rev Psiquiatr Clin. 2003;30:121-5.

Barbosa WB, Guerra Jr AA, Lemos LL, Gomes RM, Costa JD, Acurcio FA. Costs with high-cost drugs for patients with schizophrenia attended by Brazilian public health system in eleven years follow-up. Value Health. 2016:19:A1-A318.

Chimurkar LV, Reddy PS, Verma S. Pharmacoeconomic study of various brands of antipsychotic medications. Int J Pharmcol Ther. 2014;4:1:19-22.

Chisholm D, Knapp M, Knudsen C, Amaddeo F, Gaite A, Wijngaarden B. Client Socio-Demographic and Service Receipt Inventory - European Version: Development of an instrument for international research Brit J Psychiatry. 2000;177:39: s28-s33.

Chisholm D, Gureje O, Saldivia S, Calderón MV, Wickremasinghe R, Mendis N, et al. Schizophrenia treatment in the developing world: an interregional and multinational cost-effectiveness analysis. Bull WHO. 2008;86:7:497-576. 
Correll CU, Ng-Mak DS, Stafkey-Mailey D, Farrelly E, Rajagopalan K, LoebelA. Cardiometabolic comorbidities, readmission, and costs in schizophrenia and bipolar disorder: a real-world analysis. Ann Gen Psychiatry. 2017;16:9.

Elkis H, Gama C, Suplicy H, Tambascia M, Bressan R, Lyra R, et al. Brazilian Consensus on second-generation antipsychotics and metabolic disorders. Rev Bras Psiquiatr. 2008;3:1:77-85.

Goff DC, Falkai P, Fleischhacker W, Girgis RR, Kahn RM, Uchida H, et al. The long-term effects of antipsychotic medication on clinical course in schizophrenia. Am J Psychiatry Advance. 2017. doi: 10.1176/appi. ajp.2017.16091016.

Haro JM, Kamath SA, Ochoa S, Novick D, Rele K, Fargas A, et al.; SOHO Study Group. The Clinical Global Impression-Schizophrenia scale: a simple instrument to measure the diversity of symptoms present in schizophrenia. Acta Psychiatr Scand Suppl. 2003;(416):16-23.

Heinrichs D, Hanlon T, Carpenter W. The Quality of Life Scale: an instrument for rating the schizophrenic deficit syndrome. Schizophr Bull. 1984;10:388-98.

Husselman D, Joubert R, Burger JR, Lubbe MS, Cockeran M. Maximum potential cost-savings attributable to generic substitution of antipsychotics 2008 to 2013. Health SA Gesondheid. 2016;21:356-63.

Kayo M, Cardoso A, Becker P, Sousa A, Razzouk D. The lack of costeffectiveness studies and the decision-making process in low and middle-income countries: the case of antipsychotics. In: 11 ENMESHEuropean Network For Mental Health Service Evaluation, Málaga. 2015.

Kayo M, Razzouk D. Cost-Effectiveness of Antipsychotics in the Treatment of Schizophrenia Disorders. In: Razzouk D (eds). Mental Health Economics: The costs and benefits of psychiatric care. Springer International Publishing, 2017.

Kendall, T. The rise and fall of the atypical antipsychotics. Brit J Psychiatry. 2011;199:266-8.

Knapp M, Razzouk D. Economic evaluation, and schizophrenia. In: Kasper S, Papadimitriou GN, editors. Schizophrenia: biopsychosocial approaches and current challenges. 2nd ed. London: Informa Healthcare; 2009. p. 347-61.

Koskinen H, Hennamari Mikkola H, Saastamoinen K, Ahola E, Martikainen JE. Time series analysis on the impact of generic substitution and reference pricing on antipsychotic costs in Finland. Value Health. 2015;18:8:1105-12.

Leucht S, Heres S, Kisslin W, Davis J. Evidence-based pharmacotherapy of Schizophrenia. Intl J Neuropsychopharmacology. 2011;14:269-84.

Lima LA, Goncalves S, Pereira BB, Lovisi GM. The measurement of social disablement and assessment of psychometric properties of the Social Behaviour Schedule (SBS-BR) in 881 Brazilian long-stay psychiatric patients. Int J Soc Psychiatry. 2006;52:101-9.

Lindner LM, Marasciulo AC, Farias MR, Grohs GEM. Economic evaluation of antipsychotic drugs for schizophrenia treatment within the Brazilian Healthcare System Rev Saúde Pública. 2009;43:(Suppl. 1):62-9.
Lubinga SJ, Mutamba BB, Nganizi A, Babigumira JB. A cost-effectiveness analysis of antipsychotics for treatment of schizophrenia in Uganda. Appl Health Econ Health Policy. 2015;13:5:493-506.

Luz TCB, Osorio-de-Castro CG, Mangarino-Torres R, Wettermak B. Trends in medicines procurement by the Brazilian federal government from 2006 to 2013. PlosOne. 2017;12:e0174616.

Meltzer DO, Basu A, Meltzer HY. Comparative Effectiveness Research for Antipsychotic Medications: How Much Is Enough? Health Aff. 2009;28:5:w794-w808.

Ministry of Health, Brazil. Entendendo a incorporação de tecnologias em saúde no SUS. Ministério da Saúde, Secretaria de Ciência, Tecnologia e Insumos Estratégicos, Departamento de Gestão e Incorporação de Tecnologias em Saúde. Brasília, Ministério da Saúde, 2016.

Ministry of Health, Brazil. Banco de Preços em Saúde, 2017. Available from: http://saude.gov.br/bps. Acesso em: 11/07/2017.

Mullins CD, Seal B, Seoane-Vazquez E, Sankaranarayanan J, Asche CV, Jayadevappa R, et al. Good research practices for measuring drug costs in cost-effectiveness analyses: Medicare, Medicaid and other US Government payers perspectives: The ISPOR Drug Cost Task Force Report-Part IV. Value Health. 2010;13:18-24.

Nuss P, Taylor D, Hert M, Hummer M. The Generic Alternative in Schizophrenia Opportunity or Threat? CNS Drugs. 2004;18:12:769-75.

Pinto M, Santos M, Trajman A. Cost-effectiveness threshold: is it needed in Brazil? J Bras Econ Saúde. 2016;8:1:58-60.

Razzouk D, Kayo M, Sousa A, Gregorio G, Cogo-Moreira H, Cardoso AA, et al. The impact of antipsychotic polytherapy costs in the public health care in Sao Paulo, Brazil. PLoS One. 2015;10:4:e0124791.

Rosenheck R, Sernyak MJ. Developing a policy for second-generation antipsychotic drugs. Health Aff. 2009;28:5:w782-w793.

Santos AS, Vidal CEL, Brandao CMR. Cost-effectiveness of atypical antipsychotics for the treatment of schizophrenia. J Bras Econ Saúde. 2016:8:3:204-15

Silva ALF, Ribeiro RA, Santos VCC, Elias FTS, d'Oliveira ALP, Polanczyk CA. Guidelines for budget impact analysis of health technologies in Brazil. Cad. Saúde Pública, 2012;28:7:1223-38.

Sousa A, Cardoso A, Oliveira GG, Mari JJ, Razzouk D. Standardized Tool for Measurement of Health Services Costs and Utilization in a Sample with Mental Disorders: Translation, Cultural Adaptation and Interrater Reliability of the Client Socio-demographic and Service Receipt Inventory Brazilian Version. Value Health Regional Issues. 2013;16:696.

Sousa A, Razzouk D. Economic data collection: instruments for measuring health service use and direct health costs: the bottom up approach. In: Razzouk D (ed.). Mental Health Economics: The costs and benefits of psychiatric care. 1 ed.: Springer International Publishing, 2017. 